\title{
Estimating Benefits from Immunesuppressive Treatment in Diffuse Cutaneous Systemic Sclerosis: Data from the Canadian Scleroderma Research Group*
}

\author{
Tommy Choy1, Murray Baron², Janet E. Pope ${ }^{1,3 \#}$ \\ ${ }^{1}$ Schulich School of Medicine \& Dentistry, University of Western Ontario, London, Ontario, Canada \\ ${ }^{2}$ McGill University, Montreal, Canada \\ ${ }^{3}$ Department of Medicine, Division of Rheumatology, St. Joseph's Health Care, London, Ontario, Canada \\ Email: ${ }^{*}$ janet.pope@sjhc.london.on.ca
}

Received 16 September 2014; revised 16 October 2014; accepted 6 November 2014

Copyright (C) 2014 by authors and Scientific Research Publishing Inc.

This work is licensed under the Creative Commons Attribution International License (CC BY).

http://creativecommons.org/licenses/by/4.0/

(c) (i) Open Access

\begin{abstract}
Objective: To determine the efficacy of immunesuppressive treatment over 1 year in early diffuse cutaneous systemic sclerosis (dcSSc). Methods: dcSSc patients with less than 3 years disease duration and at least one year of data enrolled in the CSRG database were included. Regression analyses for achieving at least minimal important differences (MID) for 5 outcomes over one year were done to determine baseline predictors of change and if immunesuppressive treatment yielded the attainment of the MID. Results: 124 patients (mean age 52.3 years; $79.2 \%$ female) were included. Variables associated with MID at one year were often the baseline variable and for some outcomes, age, sex, smoking, restrictive lung disease and treatment type. Treatment with immunesuppressive was not found to be associated with achieving MIDs in multivariate analyses. Conclusion: Treatment was associated with achieving a MID change at 1 year using univariate statistics, but not in multivariate models. These observational data do not support improvement with immunesuppressives over one year but there could be confounding or biases comparing with those prescribed immunesuppressives vs. those who don't.
\end{abstract}

\section{Keywords}

\section{Immunesuppressive Treatment, Diffuse Cutaneous Systemic Sclerosis}

\footnotetext{
${ }^{*}$ On behalf of the Canadian Scleroderma Research Group (CSRG). Investigators of the CSRG: M. Baron, Montreal, Quebec; M. Hudson, Montreal Quebec; J. Markland, Saskatoon, Saskatchewan (now deceased); P. Docherty, Moncton, New Brunswick; M.J. Fritzler, Calgary, Alberta; N. Jones, Edmonton, Alberta; E. Kaminska, Hamilton, Ontario; N. Khalidi, Hamilton, Ontario; S. Ligier, Montreal, Quebec; A. Masetto, Sherbrooke, Quebec; J.-P. Mathieu, Montreal, Quebec; J.E. Pope, London, Ontario; D. Robinson, Winnipeg, Manitoba; D. Smith, Ottawa, Ontario; E. Sutton, Halifax, Nova Scotia.

"Corresponding author.
}

How to cite this paper: Choy, T., Baron, M. and Pope, J.E. (2014) Estimating Benefits from Immunesuppressive Treatment in Diffuse Cutaneous Systemic Sclerosis: Data from the Canadian Scleroderma Research Group. Open Journal of Rheumatology and Autoimmune Diseases, 4, 248-253. http://dx.doi.org/10.4236/ojra.2014.44034 


\section{Introduction}

Systemic Sclerosis (SSc) is a rare connective tissue disease with two main subtypes: limited cutaneous SSc (lcSSc) that affects the skin in the head and neck and that is distal to the elbows and/or knees, while diffuse cutaneous (dcSSc) also affects proximal regions and the trunk [1]. Damage is more likely in dcSSc [2].

Various outcome measurements track disease activity and progression. The Health Assessment Questionnaire (HAQ), which assesses the ability to perform daily functions, is validated in SSc [3]. The physician global assessment (MDGA), patient global assessment (PTGA) and modified Rodnan skin score (MRSS) [3] are commonly used in SSc studies. The minimally important difference (MID) is defined as the smallest difference in scores of a measure that may be considered important to a patient and could influence management. The $75^{\text {th }}$ percentile of the scores for improvement or worsening has been used in the past as a cut-off for MID [4]. Estimation of the MID is linked to clinically relevant anchors and previous studies have estimated MID for outcome measures in SSc [5] [6].

Baseline outcome measures are correlated with subsequent changes in outcome measures [7]. One year of cyclophosphamide treatment resulted in more treated patients achieving the MID for HAQ, compared to placebo [8]. Observational databases can help to demonstrate treatment benefits but often baseline differences in the outcome measurement are not taken into consideration. The Canadian Scleroderma Research Group (CSRG), which enrols incident and prevalent SSc patients into a comprehensive database, was used to explore the effect of different treatments with respect to whether or not patients achieved MID changes in skin score, global assessment and HAQ in early dcSSc after 1 year of treatment with immunesuppressive drugs and/or steroids vs. no treatment. The results could potentially help to support comparative treatment options in dcSSc.

\section{Methods}

CSRG collects annual data on SSc patients (diagnosed by their rheumatologist) from 15 centers. The database contains: self-reported data (demographics and questionnaires), dates of symptom onset, disease duration (time since onset of first non-Raynaud's symptom), current and past medications, physical examination characteristics, MRSS, organ parameters, disease activity, severity and damage scores, autoantibodies and laboratory parameters. Medication use was documented as never, ever or currently taking. All statistical analyses were performed with SPSS Statistics 21.

dcSSc patients who had completed study visits with a disease duration $<3$ years and had at least one year of data were included. The relationship between variables at baseline with outcomes at 12 months was examined. A case had to initially at the first visit not be receiving steroids and immunesuppressives and at one year was on immunesuppressive treatment vs. a control who was not on this treatment at either visit. The MID of five outcome measures were evaluated: 1) HAQ (change of 0.125 units out of 3); 2) MDGA (change of 1.0 unit out of 10); 3) PTGA (change of 1.0 unit out of 10); 4) Pain (change of 1.4 units out of 10); 5) Modified Rodnan Skin Score (change of 8 units). Factors examined at baseline included in the univariate analyses were: treatment type (immunosuppressives, corticosteroids, both immunesuppresives and steroids, no treatment), age, gender, disease duration, smoking status, post-secondary education, ESR, CRP, TLC \% predicted, FVC \% predicted, DLCO \% predicted, HAQ, pain, MDGA, PTGA, and MRSS. Unadjusted relationship between the MID outcomes and predictor variables were calculated using independent sample $t$ tests for continuous variables and Chi-square analysis for categorical variables. Multivariate analyses with stepwise logistic regression were done to explore for the effect of treatment on outcome measures after adjusting for baseline covariates. Univariate variables were included into a regression model when $\mathrm{P}<0.1$; whereas a two tailed $\mathrm{P}<0.05$ was considered statistically significant in the regression model. Several different models were studied such as combining all the immunesuppressive treatment groups into one to improve power, and studying mean changes as opposed to achieving MID.

\section{Results}

The database contained 1434 patients, most of whom had long disease duration (mean disease duration 10 years) and $60 \%$ had lcSSc. One hundred twenty-five patients met the study inclusion criteria. Twelve received prednisone alone and 23 in combination with immunesuppressives; 38 received immunesuppressives alone (27 on methotrexate, 5 on cyclophosphamide and 6 on mycophenolate mofetil) (Figure 1). Their mean age was 52.3 (SD 11.94); and $79.2 \%$ were female; $52.5 \%$ had post-secondary education and $11.5 \%$ were current smokers. The 


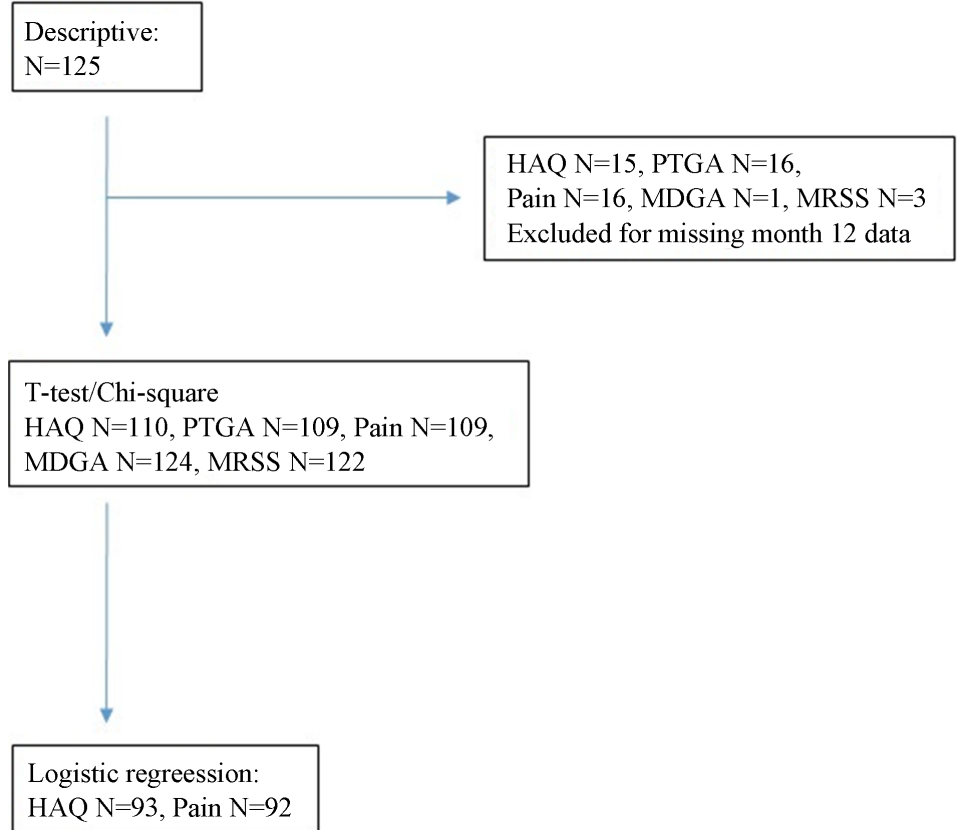

Figure 1. Disposition of patients used for this study from the Canadian Scleroderma Research Group, HAQ Health Assessment Questionnaire Disability Index, PTGA Patient Global Assessment, MDGA MD Global Assessment, and MRSS Modified Rodnan Skin Score.

percentages of patients who achieved MID were: $40.4 \%$ for pain, 54.1\% for PTGA, 39.5\% for MDGA, 32.7\% for HAQ and 36.1\% for MRSS (Table 1). At baseline; MDGA was worst on those only receiving steroids and no immunesuppressives; HAQ was lowest for those on no steroids or immunesuppressives and on follow-up that strata had the least with at least a MID improvement.

The factors at baseline associated with achieving or not at least a MID for PTGA were: age, baseline PTGA and pain, smoking status and treatment type; whereas achieving at least a MID for pain was associated with baseline PTGA, pain, HAQ and CRP. Achieving a MID of MDGA at 1 year was related to baseline MDGA, HAQ, MRSS and sex. For the MID of HAQ there were statistically significant associations of baseline PTGA, pain, HAQ, TLC\% predicted, FVC\% predicted and treatment type. Only MRSS at baseline was found to be associated with the MID of MRSS at 1 year. Treatment type was not found to be associated with MIDs for PTGA and HAQ in subsequent multivariate analyses (data not shown). The other exploratory models similarly did not find treatment type to be associated with achieving MIDs in multivariate analyses (Table 2).

\section{Discussion}

SSc is a complex disease. Reasons for treatment are largely confounded in observational cohorts. Different methods have been used to explore the effect of treatment on the progression of disease. In one study by Soliman et al., effectiveness of rituximab in rheumatoid arthritis was demonstrated without the use of controls [9]. On the other hand, Jordan et al. performed a matched control study using data from the EUSTAR group to support the effects and safety of rituximab in systemic sclerosis [10]. Contrary to these studies, we used logistic regression to estimate the attributed effect of treatment with unmatched patients from the CSRG who also met the inclusion criteria of early dcSSc with at least one year of follow up. This method allowed us to control for many factors when comparing outcomes. Strength in the current study is that adjusting for baseline differences that were significant may have reduced channelling bias.

In our study, we were unable to demonstrate any significant effects by treatment types in achieving a MID in improvement of outcomes. Unlike others which measured statistical change in a particular outcome, our emphasis was on achieving clinically important differences. This is a more conservative outcome and could explain a lack of treatment effect. Any database where treatment is not standardized likely has confounding by indication, 
Table 1. Baseline characteristics of early diffuse cutaneous patients from the Canadian Scleroderma Research Group (CSRG) database included in the analyses.

\begin{tabular}{|c|c|c|c|c|c|c|}
\hline & $\begin{array}{c}\text { Baseline } \\
\text { Total }(n=125)\end{array}$ & $\begin{array}{l}\text { No treatment } \\
\quad(\mathrm{n}=52)\end{array}$ & $\begin{array}{l}\text { Steroids only } \\
\quad(\mathrm{n}=12)\end{array}$ & $\begin{array}{c}\text { Immunosuppressives* } \\
\text { only }(\mathrm{n}=38)\end{array}$ & $\begin{array}{c}\text { Both }^{* *} \\
\text { (Steroids + Immunosuppressives) } \\
(\mathrm{n}=23)\end{array}$ & $\mathrm{P}$ \\
\hline $\begin{array}{l}\text { Disease duration, years } \\
\text { (SD) }\end{array}$ & $1.6(0.7)$ & $1.6(0.7)$ & $1.6(0.8)$ & $1.9(0.7)$ & $1.4(0.6)$ & 0.102 \\
\hline Age, years (SD) & $52.3(11.9)$ & $53.4(12.2)$ & $56.0(14.9)$ & $51.2(11.5)$ & $50.0(10.4)$ & 0.429 \\
\hline Female (\%) & 99 (79.2) & $41(78.8)$ & $9(75.0)$ & $32(84.2)$ & 17 (73.9) & 0.777 \\
\hline Current smoker (\%) & $14(11.5)$ & $5(9.8)$ & $2(16.7)$ & $5(13.5)$ & $2(9.1)$ & 0.989 \\
\hline $\begin{array}{l}\text { Post high school } \\
\text { education (\%) }\end{array}$ & $64(52.5)$ & $30(58.8)$ & $4(33.3)$ & 17 (45.9) & $13(59.1)$ & 0.307 \\
\hline $\begin{array}{l}\text { PTGA overall health } \\
\text { (SD) } \\
(0-10 \text { VAS })\end{array}$ & $4.3(2.6)$ & $3.3(2.5)$ & $6.1(2.4)$ & $4.5(2.2)$ & $5.1(2.4)$ & 0.001 \\
\hline $\begin{array}{l}\text { MID PTGA achieved } \\
\text { (\%) }\end{array}$ & $59(54.1)$ & $18(40.0)$ & $9(75)$ & $18(56.3)$ & $14(66.7)$ & 0.038 \\
\hline $\begin{array}{c}\text { Pain (SD) } \\
(0-10 \text { VAS) }\end{array}$ & $3.9(2.8)$ & $3.1(2.5)$ & $3.8(3.1)$ & $4.7(2.8)$ & $4.6(3.1)$ & 0.051 \\
\hline MID pain achieved (\%) & $44(40.4)$ & $17(37.8)$ & $3(36.4)$ & $13(40.6)$ & $10(47.6)$ & 0.883 \\
\hline $\begin{array}{l}\text { MDGA overall health } \\
\text { (SD) } \\
(0-10 \text { VAS })\end{array}$ & $4.3(2.3)$ & $3.5(2.2)$ & $5.3(2.4)$ & $4.4(2.1)$ & $5.2(2.4)$ & 0.007 \\
\hline $\begin{array}{l}\text { MID MDGA achieved } \\
(\%)\end{array}$ & 49 (39.5) & $19(36.5)$ & 7 (58.3) & 15 (39.5) & $8(36.4)$ & 0.560 \\
\hline $\begin{array}{l}\text { HAQ (SD) } \\
\quad(0-3)\end{array}$ & $1.05(0.72)$ & $0.83(0.70)$ & $1.21(0.84)$ & $1.21(0.71)$ & $1.22(0.60)$ & 0.040 \\
\hline MID HAQ achieved (\%) & 36 (32.7) & $10(21.3)$ & $6(54.5)$ & $15(48.4)$ & $5(23.8)$ & 0.025 \\
\hline Skin score (SD) (0 - 51) & $21.0(10.6)$ & $\begin{array}{c}21.1 \\
(10.3)\end{array}$ & $21.1(10.4)$ & $21.5(11.0)$ & $20.0(11.3)$ & 0.961 \\
\hline $\begin{array}{c}\text { MID skin score achieved } \\
\text { (\%) }\end{array}$ & $44(36.1)$ & 17 (33.3) & $5(41.7)$ & 15 (39.5) & $7(33.3)$ & 0.899 \\
\hline $\mathrm{ESR}$ in $\mathrm{mm} / \mathrm{hr}$ & $24.1(23.0)$ & $23.5(26.1)$ & $18.4(9.2)$ & 27.5 (23.7) & $23.6(19.7)$ & 0.698 \\
\hline CRP in mg/L (SD) & $10.1(14.7)$ & $6.4(6.3)$ & $13.0(20.4)$ & $9.4(8.3)$ & $19.0(27.0)$ & 0.013 \\
\hline TLC \% predicted (SD) & $91.0(18.0)$ & $91.0(18.0)$ & $94.1(21.4)$ & $91.5(16.0)$ & $89.0(19.4)$ & 0.921 \\
\hline FVC \% predicted (SD) & $87.4(18.7)$ & $87.4(18.7)$ & $95.3(18.0)$ & $88.6(18.0)$ & $79.6(18.9)$ & 0.092 \\
\hline DLCO \% predicted (SD) & $68.7(19.7)$ & $68.7(19.7)$ & $65.4(19.2)$ & $68.7(20.5)$ & $56.9(19.4)$ & 0.014 \\
\hline
\end{tabular}

SD: Standard deviation; PTGA: Patient global assessment; VAS: Visual analog scale; MID: Minimal important difference; MDGA: MD global assessment; HAQ: Health assessment questionnaire disability index; Skin Score: Modified rodnan skin score; ESR: Erythrocyte sedimentation rate; CRP: C-reactive protein; TLC: Total lung capacity; FVC: Forced vital capacity; DLCO: Diffusion capacity of carbon monoxide. ${ }^{*}$ methotrexate $\mathrm{n}=$ 27; cyclophosphamide $\mathrm{n}=5$; mycophenolate mofetil $\mathrm{n}=6 .{ }^{* * *}$ methotrexate $\mathrm{n}=12$; azathioprine $\mathrm{n}=2$; cyclophosphamide $\mathrm{n}=7$; mycophenolate mofetil $n=2$.

where by patients who receive treatment are different from those who do not. Similar to other studies, the baseline outcome data was often correlated with the change in outcome.

Data were collected by many centres throughout Canada, so the results may be more generalizable than a single-centre study. However, from the CSRG database a clinician's reasons for prescribing any drug could not be confirmed. A patient not taking a medication could have been due to lack of prescription, side effects, non-adherence or other factors such as limited finances for relatively expensive therapies. Patients might have also been awaiting coverage for treatments. Alternatively, a patient's treatment could have been started just before 
Table 2. Analysis of outcome measures and baseline variables.

\begin{tabular}{|c|c|c|c|c|c|}
\hline & $\begin{array}{c}\text { MID PTGA } \\
\text { P value, univariate }\end{array}$ & $\begin{array}{c}\text { MID Pain } \\
\text { P value, univariate }\end{array}$ & $\begin{array}{c}\text { MID MDGA } \\
\text { P value, univariate }\end{array}$ & $\begin{array}{c}\text { MID HAQ } \\
\text { P value, univariate }\end{array}$ & $\begin{array}{c}\text { MID skin score } \\
\text { P value, univariate }\end{array}$ \\
\hline $\begin{array}{l}\text { Disease } \\
\text { duration, years } \\
\text { (SD) }\end{array}$ & 0.849 & 0.150 & 0.440 & 0.823 & 0.542 \\
\hline Age, years (SD) & 0.101 & 0.607 & 0.294 & 0.473 & 0.291 \\
\hline $\begin{array}{l}\text { PTGA overall } \\
\text { health (SD) }\end{array}$ & $<0.001$ & 0.001 & 0.346 & 0.001 & 0.943 \\
\hline PTGA pain (SD) & 0.023 & $<0.001$ & 0.497 & 0.010 & 0.417 \\
\hline $\begin{array}{l}\text { MDGA overall } \\
\text { health (SD) }\end{array}$ & 0.129 & 0.198 & $<0.001$ & 0.209 & 0.202 \\
\hline HAQ (SD) & 0.072 & 0.004 & 0.036 & $<0.001$ & 0.194 \\
\hline Skin score (SD) & 0.721 & 0.558 & 0.016 & 0.113 & 0.004 \\
\hline $\mathrm{ESR}$ in $\mathrm{mm} / \mathrm{hr}$ & 0.358 & 0.163 & 0.107 & 0.631 & 0.988 \\
\hline $\begin{array}{l}\text { CRP in mg/L } \\
\text { (SD) }\end{array}$ & 0.081 & 0.028 & 0.059 & 0.308 & 0.690 \\
\hline $\begin{array}{l}\text { TLC \% predicted } \\
\text { (SD) }\end{array}$ & 0.260 & 0.436 & 0.971 & 0.016 & 0.674 \\
\hline $\begin{array}{l}\text { FVC \% predicted } \\
\text { (SD) }\end{array}$ & 0.754 & 0.716 & 0.642 & 0.012 & 0.905 \\
\hline $\begin{array}{c}\text { DLCO \% } \\
\text { predicted (SD) }\end{array}$ & 0.151 & 0.197 & 0.531 & 0.554 & 0.184 \\
\hline $\begin{array}{c}\text { Female gender } \\
\text { (\%) }\end{array}$ & 0.965 & 0.954 & 0.093 & 0.792 & 0.994 \\
\hline $\begin{array}{c}\text { Current smoker } \\
\text { (\%) }\end{array}$ & 0.031 & 0.963 & 0.257 & 0.736 & 0.718 \\
\hline $\begin{array}{l}\text { Post secondary } \\
\text { education (\%) }\end{array}$ & 0.097 & 0.586 & 0.976 & 0.584 & 0.105 \\
\hline Treatment type & 0.038 & 0.883 & 0.560 & 0.025 & 0.899 \\
\hline
\end{tabular}

MID: Minimal important difference; PTGA: Patient global assessment; MDGA: MD global assessment; HAQ: Health assessment questionnaire disability index; Skin Score: Modified rodnan skin score; ESR: Erythrocyte sedimentation rate; CRP: C-reactive protein; TLC: Total lung capacity; FVC: Forced vital capacity; DLCO: Diffusion capacity of carbon monoxide.

the visit, so some patients may not have received an entire year of treatment. These factors may have led to an overestimation or underestimation in the number of patients receiving treatment (misclassification of considering treatment for an entire year instead of actual treatment duration). There was no clear signal that treatment made a difference over one year in these patients, which is contrary to regression to the mean where those with the highest scores may have experienced more improvement over one year of follow up. Some may consider the MID of 8 units on the MRSS to be high, but this was suggested in the literature [5]. However, experts have determined that a lower change in skin score is clinically relevant [11]. We did not study response to treatment by antibodies due to the small numbers of patients in this study.

Observational cohort studies and case series are used to estimate treatment effects and this negative study may be due to multiple biases. However, it is also important to consider that in the one year time frame the patients did experience improvement when adjusting for baseline differences between those who received vs. did not receive immunesuppressive therapy.

\section{Conclusion}

Treatment was found to be significantly associated with achieving a change in the MID at 1 year for HAQ and pain score at the univariate level, but not when using multivariate adjustments. Future studies on observational 
cohorts may also need to adjust for confounders and try to reduce bias.

\section{Conflicts of Interest}

There are no conflicts of interest/nothing to declare. Ethics approval and informed consent was obtained for all patients.

\section{Funding}

The Canadian Scleroderma Research Group (CSRG) is funded by the Canadian Institutes of Health Research (CIHR), Scleroderma Society of Canada, Scleroderma Society of Ontario, Cure Scleroderma Foundation.

\section{References}

[1] Merkel, P.A., Silliman, N.P., Clements, P.J., Denton, C.P., Furst, D.E., Mayes, M.D., et al. (2012) Patterns and Predictors of Change in Outcome Measures in Clinical Trials in Scleroderma: An Individual Patient Meta-Analysis of 629 Subjects with Diffuse Cutaneous Systemic Sclerosis. Arthritis \& Rheumatism, 64, 3420-3429. http://dx.doi.org/10.1002/art.34427

[2] Hudson, M., Steele, R., Lu, Y., Thombs, B.D., Panopalis, P., Baron, M., et al. (2009) Clinical Correlates of Self-Reported Physical Health Status in Systemic Sclerosis. The Journal of Rheumatology, 36, 1226-1229. http://dx.doi.org/10.3899/jrheum.081057

[3] Pope, J. (2011) Measures of Systemic Sclerosis (Scleroderma): Health Assessment Questionnaire (HAQ) and Scleroderma HAQ (SHAQ), Physician- and Patient-Rated Global Assessments, Symptom Burden Index (SBI), University of California, Los Angeles, Scleroderma Clinical Trials Consortium Gastrointestinal Scale (UCLA SCTC GIT) 2.0, Baseline Dyspnea Index (BDI) and Transition Dyspnea Index (TDI) (Mahler's Index), Cambridge Pulmonary Hypertension Outcome Review (CAMPHOR), and Raynaud's Condition Score (RCS). Arthritis Care \& Research (Hoboken), 63, S98-S111.

[4] Beaton, D.E., Boers, M. and Wells, G.A. (2002) Many Faces of the Minimal Clinically Important Difference (MCID): A Literature Review and Directions for Future Research. Current Opinion in Rheumatology, 14, 109-114. http://dx.doi.org/10.1097/00002281-200203000-00006

[5] Khanna, D., Furst, D.E., Hays, R.D., Park, G.S., Wong, W.K., Seibold, J.R., et al. (2006) Minimally Important Difference in Diffuse Systemic Sclerosis: Results from the D-Penicillamine Study. Annals of the Rheumatic Diseases, 65, 1325-1329. http://dx.doi.org/10.1136/ard.2005.050187

[6] Sekhon, S. and Pope, J., Canadian Scleroderma Research Group and Baron M. (2010) The Minimally Important Difference in Clinical Practice for Patient-Centered Outcomes Including Health Assessment Questionnaire, Fatigue, Pain, Sleep, Global Visual Analog Scale, and SF-36 in Scleroderma. The Journal of Rheumatology, 37, 591-598. http://dx.doi.org/10.3899/jrheum.090375

[7] Lawrence, E., Pope, J., Al-Zahraly, Z., Lalani, S. and Baron, M. (2009) The Relationship between Changes in SelfReported Disability (Measured by the Health Assessment Questionnaire-HAQ) in Scleroderma and Improvement of Disease Status in Clinical Practice. Clinical and Experimental Rheumatology, 27, 32-37.

[8] Khanna, D., Yan, X., Tashkin, D.P., Furst, D.E., Elashoff, R., Roth, M.D., et al. (2007) Impact of Oral Cyclophosphamide on Health-Related Quality of Life in Patients with Active Scleroderma Lung Disease: Results from the Scleroderma Lung Study. Arthritis \& Rheumatism, 56, 1676-1684. http://dx.doi.org/10.1002/art.22580

[9] Soliman, M.M., Hyrich, K.L., Lunt, M., Watson, K.D., Symmons, D.P., Ashcroft, D.M., et al. (2012) Effectiveness of Rituximab in Patients with Rheumatoid Arthritis: Observational Study from the British Society for Rheumatology Biologics Register. The Journal of Rheumatology, 39, 240-246. http://dx.doi.org/10.3899/jrheum.110610

[10] Jordan, S., Distler, J.H., Maurer, B., Huscher, D., van Laar, J.M., Allanore, Y., et al. (2014) Effects and Safety of Rituximab in Systemic Sclerosis: An Analysis from the European Scleroderma Trial and Research (EUSTAR) Group. Annals of the Rheumatic Diseases, Published Online First 17 January 2014. http://dx.doi.org/10.1136/annrheumdis-2013-204522

[11] Gazi, H., Pope, J., Clements, P., Medsger, T., Martin, R., Kahaleh, B., et al. (2007) Outcome Measurements in Scleroderma. The Journal of Rheumatology, 34, 501-509. 
Scientific Research Publishing (SCIRP) is one of the largest Open Access journal publishers. It is currently publishing more than 200 open access, online, peer-reviewed journals covering a wide range of academic disciplines. SCIRP serves the worldwide academic communities and contributes to the progress and application of science with its publication.

Other selected journals from SCIRP are listed as below. Submit your manuscript to us via either submit@scirp.org or Online Submission Portal.
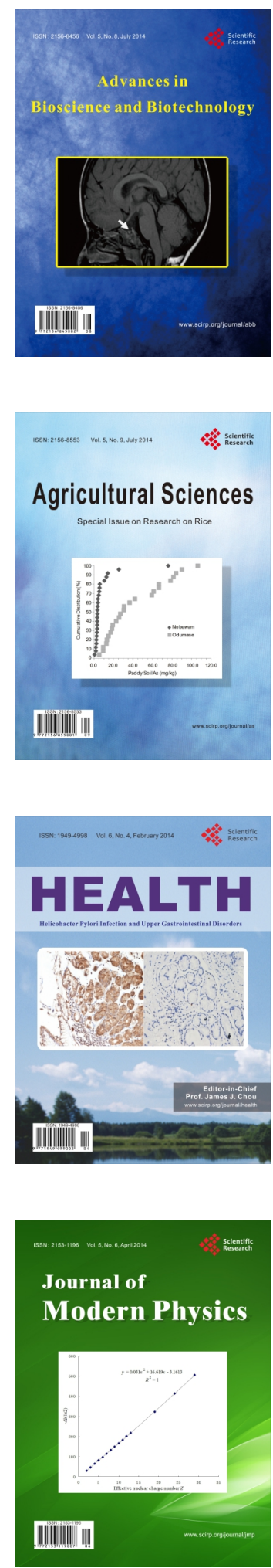
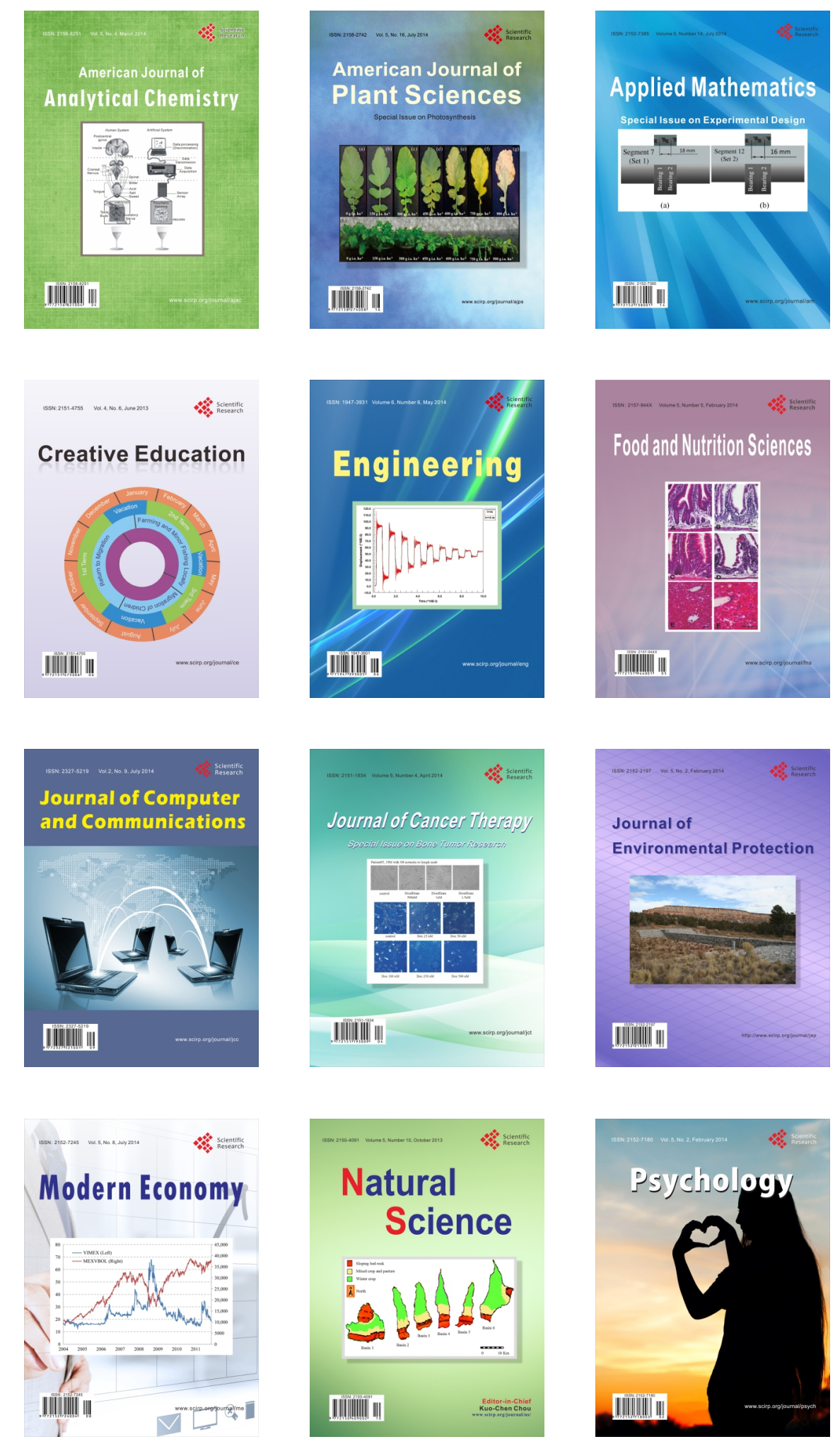